ISSN 1981-416X

Licenciado sob uma Licença Creative Commons

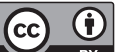

\title{
Tensionamentos entre estrutura e ação na sociologia da educação contemporânea: uma leitura comparativa entre Pierre Bourdieu e François Dubet
}

Tensions between structure and action in contemporary sociology of education: a comparative reading between Pierre Bourdieu and François Dubet

Tensionamientos entre estructura y acción en la sociología de la educación contemporánea: una lectura comparativa entre Pierre Bourdieu y François Dubet

Thiago Delaíde da Silva ${ }^{[a]}$, Rodrigo Marques Leistner ${ }^{[b]^{*}}$

\footnotetext{
[a] Universidade do Vale do Rio dos Sinos (UNISINOS), São Leopoldo, RS, Brasil

[b] Universidade Federal do Rio Grande (FURG), Rio Grande, RS, Brasil
}

\section{Resumo}

O artigo aborda os tensionamentos que concernem à relação sociedade e indivíduo, agência e sistema, estrutura e ação no âmbito da sociologia da educação contemporânea. Para tal empreendimento, e com base numa reflexão de cunho eminentemente teórico, o texto coloca em relevo uma leitura comparativa entre as abordagens de Pierre Bourdieu e François Dubet, visando compreender não apenas o modo como aqueles tensionamentos 
se resolveram em suas elaborações teóricas, mas, sobretudo, a forma através da qual suas perspectivas - mais estruturais ou acionalistas - contribuíram para a constituição de distintos esquemas de percepção das relações sociais que envolvem os processos educacionais, gerando-se enfoques, temáticas e agendas de pesquisa específicas. Nesses termos, e de modo mais aprofundado, o texto busca averiguar as possíveis contradições, complementaridades e possibilidades de aproximação desses diferentes modelos de análise, evidenciando-se os prováveis ganhos analíticos no cruzamento das perspectivas colocadas em estudo. Como conclusão, sugere-se que a articulação entre o conceito de habitus (de Bourdieu) e a noção de experiência social (Dubet) permita elaborações teóricas mais amplas que ultrapassem as percepções das relações de poder e reprodução das desigualdades nos espaços escolares, possibilitando análises que liguem tais realidades junto à experiência da deliberação e reflexão crítica por parte dos atores sociais mediante um modelo político de educação.

Palavras-chave: Estrutura Social. Ação Social. Pierre Bourdieu. François Dubet. Sociologia da Educação.

\begin{abstract}
The article refers the tensions that concern the relationship between society and individual, agency and system, structure and action within the contemporary sociology of education. For this development, based on an eminently theoretical reflection, the text highlights a comparative reading between the approaches of Pierre Bourdieu and François Dubet, aiming to understand not only the way these tensions were solved in their theoretical elaborations, but especially the way in which their approaches - more structural or actionalist - have contributed to the constitution of different schemes of perception about the social relations that involve the educational processes. In these terms, and more specifically, the text seeks to find out the possible contradictions, complementarities and possibilities of approaching these different models of analysis, evidencing the probable analytical gains in the crossing of the perspectives under study. As a conclusion, it is suggested that the articulation between the concept of habitus (from Bourdieu) and the notion of social experience (Dubet) allows for wider theoretical elaborations that surpass the perceptions of
\end{abstract}


the power relations and reproduction of inequalities in the school spaces, that link these realities together with the experience of deliberation and critical reflection on the part of the social actors through a political model of education.

Keywords: Social Structure. Social Action. Pierre Bourdieu. François Dubet. Sociology of Education.

\section{Resumem}

El artículo aborda los tensionamientos que conciernen a la relación sociedad e individuo, agencia y sistema, estructura y acción en el ámbito de la sociología de la educación contemporánea. Para este emprendimiento, y con base en una reflexión de cuño eminentemente teórico, el texto pone de relieve una lectura comparativa entre los enfoques de Pierre Bourdieu y François Dubet, buscando comprender no sólo el modo en que esos tensos se resolvieron en sus elaboraciones teóricas, pero sobre todo la forma a través de la cual sus perspectivas - más estructurales o acionalistas - contribuyeron a la constitución de distintos esquemas de percepción de las relaciones sociales que envuelven los procesos educativos, generando enfoques, temáticas y agendas de investigación específicas. En estos términos, y de modo más específico, el texto busca averiguar las posibles contradicciones, complementariedades y posibilidades de aproximación de esos diferentes modelos de análisis, evidenciándose los probables beneficios analíticos en el cruce de las perspectivas planteadas en estudio. Como conclusión, se sugiere que la articulación entre el concepto de habitus (de Bourdieu) y la noción de experiencia social (Dubet) permita elaboraciones teóricas más amplias que sobrepasen las percepciones de las relaciones de poder y reproducción de las desigualdades en los espacios escolares, posibilitando análisis que enlazan tales realidades junto a la experiencia de la deliberación y reflexión crítica por parte de los actores sociales mediante un modelo político de educación.

Keywords: Estructura Social. Acción Social. Pierre Bourdieu. François Dubet. Sociología de la Educación. 


\section{Introdução}

O desenvolvimento das ciências sociais sempre esteve permeado por uma série de tensionamentos relacionados aos possíveis pontos de partida para a observação da realidade social, cultural ou política. Assim, os paradigmas da área foram constituídos com base em diversas oposições epistemológicas, aqui confrontando-se noções como integração e ruptura, sincronismo e diacronismo, ideologia e utopia, comunidade e sociedade (IANNI, 1989). No caso específico da sociologia, boa parte dessas tensões pode ser percebida através de dualidades como sociedade e indivíduo, sistema e agência, estrutura e ação, cujos sentidos se referem aos princípios explicativos básicos das relações sociais, ora focados na observação das estruturas que incidem sobre tais relações, ora voltados para a percepção das ações individuais que constituem a sociedade, ou ainda direcionados à verificação do caráter dialógico presente nesses processos, aqui considerando-se a complementaridade entre agência e sistema na configuração dos processos sociais (GAIGER, 1999).

Como se sabe, partiu do positivismo de Durkheim a elaboração de uma explicação sociológica centrada nas estruturas societárias, com base na ideia de que as representações coletivas é que organizam a vida em sociedade, concepção que se desenvolveu mais claramente sob o conceito de Fato Social e a partir das expectativas de um conhecimento objetivo da sociedade (DURKHEIM, 2000). Noutra perspectiva, a sociologia compreensiva de Weber pressupôs a observação das experiências singulares dos indivíduos, centrando seu objeto de estudo junto ao sentido que os mesmos conferem a suas ações, a realidade social sendo concebida como resultante da conciliação de diferentes lógicas de ação individual (WEBER, 1994). Por sua vez, coube a Marx uma reflexão dialética destes processos, estrutura e ação relacionando-se na medida em que, para esse autor, não apenas as estruturas incidem sobre a organização das relações sociais, mas ainda as ações dos indivíduos podem alterar estas mesmas estruturas, desde que os sujeitos históricos se deem conta dos processos 
ideológicos que sustentam a reprodução não contraditória da sociedade (MARX; ENGELS, 1987) ${ }^{1}$.

Logicamente, tais tensionamentos não se encerram no desenvolvimento da sociologia clássica, reverberando no debate sociológico contemporâneo, seja nas perspectivas do estrutural-funcionalismo de Parsons, nas teorias acionalistas de Goffman ou ainda nas perspectivas de caráter mais dialógico, como a teoria da estruturação, de Giddens (DUBET, 1994; TOURAINE; KHOSROKHAVAR, 2001) ${ }^{2}$. E, da mesma forma, tais problemáticas não se restringem ao desenvolvimento de uma teoria geral da sociedade, incidindo sobre a configuração das sociologias específicas, seja no que se refere ao estudo das relações sociais que envolvem a dimensão do poder (a sociologia política), a normatividade (a sociologia jurídica), os valores e visões de mundo (a sociologia da cultura) ou mesmo as relações que abarcam os processos de ensino (a sociologia da educação).

Nesse último caso, em específico, e conforme sugerido por Dubet (1994), a sociologia da educação tem se constituído como exemplar para reflexões sobre o modo como diferentes concepções teóricas (mais estruturais ou acionalistas) podem ocasionar distintas perspectivas de análise. Enquanto algumas visões encontram-se mais centradas na reprodução das desigualdades e relações de poder, observando-se como as estruturas assimétricas podem se perpetuar a partir dos processos de ensino e das instituições escolares, outros enfoques, mais interessados na emergência da ação social, ajudam a compreender as formas pelas quais as mobilizações

1 De acordo com Sell (2010), o posicionamento epistemológico de Marx, no que se refere à relação sociedade e indivíduo, é complexo, observando-se diferentes percepções sobre o tema. Neste artigo, a caracterização da relação dialógica entre estrutura e ação no paradigma marxista baseiase na consideração das contradições que envolvem a infraestrutura material e a superestrutura ideológica da sociedade e as possibilidades de ação concreta que daí decorrem.

2 Como demonstra o trabalho de Leistner (2015), tais tensionamentos ocorrem mesmo dentro de uma determinada tradição teórica, caso da Escola de Frankfurt, historicamente dividida entre concepções estruturais e integracionistas e percepções mais atentas às possibilidades de ação e ruptura nos processos sociais. 
e lutas políticas também se processam nos espaços escolares, gerando-se reflexividade e atitude crítica por parte dos atores sociais envolvidos.

É com intuito de refletir sobre essas diferentes perspectivas de análise que esse trabalho se constitui. Desse modo, este artigo objetiva promover uma reflexão sobre os tensionamentos que concernem à relação sociedade e indivíduo, agência e sistema, estrutura e ação no âmbito da sociologia da educação. Tratando-se de uma reflexão de cunho teórico, a tarefa aqui proposta consiste em investigar o modo como diferentes perspectivas de análise contribuem para percepções das relações sociais que envolvem os processos educacionais.

Para circunscrever a reflexão proposta, o artigo enfoca a teoria sociológica contemporânea, promovendo uma análise comparativa entre dois dos principais autores da sociologia da educação: Pierre Bourdieu e François Dubet ${ }^{3}$. Nessa perspectiva, enquanto Bourdieu aborda as características estruturais dos processos educacionais ${ }^{4}$, privilegiando os aspectos problemáticos da reprodução das desigualdades e assimetrias nos espaços escolares, Dubet concede mais atenção às ações constitutivas dos processos de ensino, enfatizando as possibilidades de mobilização e emergência da capacidade de deliberação e reflexão crítica por parte dos atores sociais ${ }^{5}$. Desse modo, trata-se de duas concepções teóricas apropriadas para balizar a reflexão desenvolvida, observando-se, por um lado, uma perspectiva mais ligada às estruturas de poder que potencialmente

3 A referência sobre a centralidade desses autores no contexto da sociologia da educação contemporânea é compartilhada por Arenhart (2014).

4 Segundo Leistner (2009), a caracterização do trabalho de Bourdieu junto às teorias de cunho estrutural é problemática, observando-se que o conceito de habitus se refere justamente à iniciativa de superar a dualidade teórica impressa na relação agência versus estrutura, o que também é referido por Ortiz (1983). Contudo, como demonstram esses mesmos autores, a noção de habitus, bem como a teoria do campo social desenvolvida por Bourdieu, projeta muito mais atenção aos aspectos estruturais da realidade social do que às lógicas de ação potencialmente emergentes entre as atividades práticas e cotidianas dos sujeitos sociais.

5 Como observa Silva (2009), a sociologia da experiência desenvolvida por Dubet reside justamente no âmbito das teorias acionalistas, com profunda influência da obra de Simmel. 
incidem sobre a práxis e, de outro, um viés que avalia a configuração das lógicas de ação colocadas em prática pelos próprios atores.

Decerto, não se pretende aqui determinar qual posicionamento teórico seria mais compatível com os estudos da sociologia da educação, mas sim averiguar as possíveis contradições, complementaridades e possibilidades de aproximação entre diferentes modelos de análise, evidenciando-se possíveis ganhos analíticos no cruzamento das perspectivas colocadas em debate. No entanto, antes de relacionar as confrontações teóricas que organizam a análise, torna-se necessário recuperar os principais aspectos das elaborações empreendidas pelos autores referenciados, seja no âmbito da praxiologia, de Bourdieu, seja no contexto da sociologia da experiência, de Dubet, levando-se em conta suas discussões epistemológicas basilares e os principais conceitos que organizam suas teorias, bem como suas análises específicas sobre a relação entre educação e sociedade.

\section{Elementos da Praxiologia: Habitus, Campo e Capital nos espaços escolares}

O trabalho de Bourdieu parte de uma epistemologia de caráter dialógico, cujos escopos buscam superar não apenas o método sociológico objetivista, centrado nas estruturas societárias, mas também o método fenomenológico de investigação, centrado na ação dos atores sociais, sua praxiologia propondo caracterizar as mediações existentes entre sistema e agência. Segundo Ortiz (1983, p. 14), "o conhecimento praxiológico se coloca como teoria que pretende superar (e conservar) o objetivismo", buscando, pois, "encontrar uma mediação entre agente social e sociedade, entre homem e história”. É nesse empreendimento que Bourdieu desenvolve o conceito de habitus, que propõe uma conciliação analítica entre as dimensões estruturadas e estruturantes da vida social. O habitus seria uma espécie de modus operandi dos sujeitos, uma predisposição para se pensar e agir de determinada maneira, a qual é interiorizada nos processos de socialização. Nas palavras do autor, o habitus constitui: 
[...] um sistema de disposições duráveis, estruturas estruturadas predispostas a funcionarem como estruturas estruturantes, isto é, como princípio que gera e estrutura as práticas e as representações que podem ser objetivamente "regulamentadas" e "reguladas" sem que por isso sejam o produto de obediência a regras, objetivamente adaptadas a um fim, sem que se tenha a necessidade de projeção consciente deste fim ou do domínio das operações para atingi-lo, mas sendo, ao mesmo tempo, coletivamente orquestradas sem serem o produto da ação organizadora de um maestro (BOURDIEU, 1983, p. 60-61).

Isso significa que o habitus não é um conjunto de regras que determinam as ações dos sujeitos, mas uma estrutura assimilada nos processos de socialização que é incorporada pelos atores, tornando-se o meio pelo qual estes interagem com a totalidade social. O habitus é, nas palavras de Bourdieu (1983, p. 72), como "uma lei imanente que é depositada em cada agente pela educação primeira" e serve como matriz que antecede as ações dos sujeitos e direciona suas escolhas e até mesmo sua visão de mundo, sua maneira de pensar. Nesses termos, o habitus é assimilado a partir da realidade externa, possibilitando a interiorização de certos comportamentos, princípios e práticas presentes na estrutura social. E, apesar de os atores não serem necessariamente passivos neste processo, pois é possível haver resistência à incorporação das práticas ou modelos de pensamento, há uma tendência dos atores a incorporarem essas práticas tornando-as parte de si mesmos, fazendo com que ocorra uma relação de "conaturalidade" entre indivíduo e estrutura social. Por meio do habitus, sujeito e sociedade se articulam e, através desse conceito, Bourdieu observa uma tendência da sociedade à reprodução das ações, comportamentos, práticas e esquemas de pensamento, uma vez que os atores tendem a reproduzir a ordem social estabelecida.

O habitus é, para falar depressa, um produto dos condicionamentos que tende a reproduzir a lógica objetiva dos condicionamentos mas fazendo-a sofrer uma transformação; é uma espécie de máquina transformadora que faz com que "reproduzamos" as condições sociais da nossa própria produção, mas de uma maneira relativamente imprevisível, de uma maneira tal que não podemos passar simples e 
mecanicamente do conhecimento das condições de produção ao conhecimento dos produtos (BOURDIEU, 1984, p. 140).

Ainda segundo Bourdieu, os atores internalizam o habitus a partir de contextos e espaços sociais distintos, o que corrobora com a construção de outro conceito central para a percepção das relações sociais na visão do autor: o conceito de campo social. Conforme Ortiz, o campo "é o espaço onde as posições dos agentes se encontram a priori fixadas", ocorrendo disputas de poder por legitimidade e validação social, sendo "o lócus onde se trava uma luta concorrencial entre os atores em torno de interesses específicos" (ORTIZ, 1983, p. 19). Dito de outro modo, o campo é um lugar de lutas e embates por definição da realidade social (BOURDIEU, 1983, p. 123). Conforme descreve Catanni (2011, p. 192):

A noção de campo substitui a de sociedade, pois, para Bourdieu, uma sociedade diferenciada não se encontra plenamente integrada por funções sistêmicas, mas, ao contrário, é constituída por um conjunto de microcosmos sociais dotados de autonomia relativa, com lógicas e possibilidades próprias, específicas, com interesses e disputas irredutíveis ao funcionamento de outros campos.

Decerto, há muitos campos em que os sujeitos atuam e circulam durante sua vida, e cada campo possui características próprias e autonomia em relação a outros campos, cada qual apresentando uma tendência em gerar habitus específicos nos sujeitos sociais. Assim, podemos entender as diferentes esferas da sociedade como campos próprios. De acordo com Bourdieu (1989, p. 153), a sociedade é um "espaço multidimensional", não sendo uma realidade única, mas "um conjunto aberto de campos relativamente autônomos", o que significa dizer que, em cada campo, o funcionamento, as transformações, as condições e disputas internas possuem uma lógica própria que independe dos demais, embora os diferentes espaços sociais se relacionem entre si. Nessa perspectiva, podemos conceber a sociedade como composta por campos diversos, como o campo da política, da religião, da economia, da educação e assim sucessivamente, cada qual contando com categorias de atores sociais específicos que 
disputam o jogo concorrencial ativado nas lógicas endógenas desse espaço social particular.

Em todo campo social, por sua vez, ocorrem disputas por interesses particulares que caracterizam um jogo de poder próprio do espaço em questão. Conforme Bourdieu, no interior de cada campo social o que está em jogo é um tipo de poder característico que organiza a concorrência e as hierarquias endógenas desse mesmo campo, o que o autor refletirá a partir do conceito de capital. Assim, em cada campo há uma distribuição desigual do "quantum social" que determinará as relações de poder e as posições dos agentes no interior deste mesmo espaço (ORTIZ, 1983, p. 21). Faz parte da estrutura do campo social que ele seja "um estado da relação de força entre os agentes ou as instituições envolvidas na luta ou, se preferir, da distribuição do capital específico que, acumulado no decorrer das lutas anteriores, orienta as estratégias posteriores" (BOURDIEU, 1984, p. 120). Assim, todo campo surge como "uma configuração das relações socialmente distribuídas a partir da repartição das diversas formas de capital" (LEISTNER, 2009, p. 85). Dito de outro modo, a compreensão da lógica e funcionamento de um campo específico só é possível a partir da constatação acerca dos diferentes capitais em disputa nesse mesmo campo, bem como da distribuição destes capitais por entre os agentes que o compõem.

Contudo, a observação dessas relações demanda ainda a consideração de que os capitais em jogo num determinado campo possam assumir formas variadas, observando-se diferentes configurações a partir das quais o princípio que organiza as disputas pode ser percebido. Para Bourdieu (1989), o capital pode assumir a forma econômica (recursos materiais, etc.), cultural (conhecimentos adquiridos, acesso a formas de cultura, etc.), social (redes de relações sociais) ou simbólica (a qual pode incluir a posse de bens abstratos como prestígio, reputação, honra, etc.) e, embora os capitais disputados possam estar associados, é possível que, de acordo com a lógica própria de ordenamento de um campo específico, um determinado capital possa apresentar preponderância em relação a outros.

Foi com base na articulação desses elementos teóricos (habitus, campo e capital) que Bourdieu construiu sua análise do campo da 
educação, promovendo uma arguta crítica à visão otimista que pairava sobre as análises do sistema de ensino europeu ao menos até a década de 1960. Como demonstra Rodrigues (2007), a tônica dos estudos disponíveis até então esteve centrada na esperança de um sistema escolar baseado em possibilidades de emancipação social e política em virtude dos ideais de acesso universal e na perspectiva do mérito individual. Ao contrário, a análise bourdiana acerca do campo da educação - considerado nos termos de seus capitais estruturantes e habitus característico - demonstrou que os sistemas escolares configurariam muito mais um espaço de reprodução das desigualdades sociais, sobretudo a partir da legitimação da cultura dominante, numa lógica segundo a qual "a igualdade formal que pauta a prática pedagógica serve como máscara e justificação para a indiferença no que diz respeito às desigualdades reais diante do ensino e da cultura transmitida, ou, melhor dizendo, exigida" (BOURDIEU, 2007, p. 53). Isso significa, em outras palavras, que a desigualdade existente entre os atores sociais no campo social mais amplo se perpetua no campo da educação, apesar de ocorrer de maneira velada.

Dentro do espaço escolar, os conceitos de habitus, campo e capital tornam-se elucidativos. A escola, como espaço social caraterístico, possui um habitus e um conjunto de capitais colocados em disputa, observando-se práticas e regras que são previamente fixadas, implícita ou explicitamente, a que o estudante precisa se adequar e interiorizar a fim de que se saia bem nas disputas engendradas no sistema educacional. Contudo, essas ideias não se restringem às realidades experimentadas no interior do espaço escolar, verificando-se conexões importantes entre o modus operandi considerado nesse contexto e aquele característico do ambiente familiar dos alunos. Na perspectiva de Bourdieu (1983, p. 80), "o habitus adquirido na família está no princípio da estruturação das experiências escolares dos atores sociais". E esse habitus adquirido no ambiente familiar está relacionado a um capital cultural transmitido de modo inconsciente, mas que incide diretamente no desempenho escolar dos estudantes. Nas palavras do autor: 
[...] cada família transmite a seus filhos, mais por vias indiretas do que diretas, um certo capital cultural e um certo ethos, sistema de valores implícitos e profundamente interiorizados que contribui para definir, entre outras coisas, as atitudes face ao capital cultural e à instituição escolar. A herança cultural, que difere, sob os dois aspectos, segundo as classes sociais, é a responsável pela diferença inicial das crianças diante da experiência escolar, e consequentemente, pelas taxas de êxito (BOURDIEU, 2007, p. 41-42).

Dessa maneira, aqueles estudantes cujo habitus familiar e capital cultural incorporado se aproximem das formas de comportamento e desempenho exigidas pela escola e pelo "arbitrário cultural" por ela valorizados apresentam maior possibilidade de êxito e bom desempenho nas trajetórias estudantis. Como exemplo, um estudante que detém um habitus familiar no qual a leitura é algo constante e cujo capital cultural incorporado, portanto, está em sintonia com aquele valorizado na escola terá mais chance de obter êxito nos processos escolares em detrimento dos agentes cujas práticas não integrem aquele arbitrário cultural (valorizado na escola). Todavia, a escola tende a perceber o êxito daqueles que detêm os capitais valorizados em termos de uma perspectiva meritocrática, na mesma medida em que o baixo desempenho de outros (que não detêm aqueles capitais) será percebido como "fracasso individual", assim negligenciando-se questões relacionadas às diferentes origens sociais dos estudantes. Para Nogueira e Nogueira (2002, p. 21):

A educação escolar, no caso das crianças oriundas de meios culturalmente favorecidos, seria uma espécie de continuação da educação familiar, enquanto para as outras crianças significaria algo estranho, distante ou mesmo ameaçador. A posse de capital cultural favoreceria o êxito escolar, em segundo lugar, porque propiciaria um melhor desempenho nos processos formais e informais de avaliação.

Além disso, a escola tende a selecionar de modo arbitrário os conteúdos exigidos, o que por sua vez favorece os estudantes das classes dominantes que possuem uma "bagagem" mais ampla e vinculada 
ao capital cultural geralmente valorizado. Como referem Nogueira e Nogueira (2002, p. 29-30), "para os alunos das classes dominantes, a cultura escolar seria a sua própria cultura, reelaborada e sistematizada. Para os demais, seria uma cultura estrangeira". E desse modo, a escola, segundo Bourdieu, não é uma instância neutra, mas "uma instituição a serviço da reprodução e legitimação da dominação exercida pelas classes dominantes" (NOGUEIRA; NOGUEIRA, 2002, p. 28). Apesar de ocorrerem casos de superação do quadro referido, os quais, segundo Bourdieu (2007, p. 59), geram uma "aparência de legitimidade da seleção escolar", a escola tende a selecionar os mais favorecidos socialmente, promovendo a exclusão e perpetuando as desigualdades sociais.

\section{A sociologia da experiência: lógicas de ação no processo educacional}

Como se observa nas análises bourdianas sobre a educação, embora o próprio conceito de habitus tenha se constituído visando promover a mediação entre ação e estrutura, o peso conferido às lógicas de reprodução e o enfoque no modo como o habitus organiza comportamentos dentro de um campo de relações específico advertem sobre a dimensão estrutural contida na praxiologia (RODRIGUES, 2007). De maneira oposta, os estudos de François Dubet partirão de uma perspectiva tributária das teorias acionalistas, herdeiras de Max Weber e que concebem como foco de análise a questão da agência humana (CARVALHO, 1993). Assim, Dubet (1994) desenvolve sua Sociologia da Experiência a partir da constatação de que a concepção tradicional de sociedade, como sistema homogêneo, não pode mais ser imaginada uma vez que o mundo contemporâneo apresenta um esgotamento da representação social atrelada às ideias de integração. A sociedade atual, segundo o autor, não possui centro, sendo dispersa e constituída por ações múltiplas cuja compreensão só é possível na percepção das experiências cotidianas dos atores sociais.

Conforme Dubet (1994), a concepção clássica da sociedade procurou desenvolver uma perspectiva sistêmica e unificadora do social, na 
qual o indivíduo e a estrutura, ator e sistema se fundiam numa unidade integrada. Para o pensamento clássico, como o de Durkheim, o indivíduo é uma extensão da sociedade e, em boa parte dessa visão, a sociedade identifica-se com a modernidade a partir de uma realidade "integrada e integradora", que produz indivíduos que interiorizam valores e constituem-se a partir de papéis sociais bem definidos (WAUTIER, 2003, p. 177). Ao contrário, Dubet (1994) propõe que tal concepção está ameaçada e não é mais aceitável para compreender as relações sociais existentes, não explicando de maneira fidedigna a complexidade das ações dos atores num mundo contemporâneo cujos processos de integração encontram-se substancialmente matizados.

É nesse contexto que Dubet estabelece o conceito de experiência social, visando dar conta da análise das ações num contexto de múltiplas possibilidades de orientação e configuração das subjetividades. Com efeito, tal conceito diz respeito às condutas individuais e coletivas constituídas na própria heterogeneidade, bem como ao trabalho de construção, por parte dos atores, do sentido de suas práticas e lógicas de ação (DUBET, 1994). Isso significa que a experiência social não se processa a partir da homogeneidade e da integração, como na sociologia clássica hegemônica ${ }^{6}$.

É preciso ter em consideração este estilhaçamento propondo teorias de alcance médio que não tenham a ambição de integrarem a visão unificada de um mundo social que deixou de ter centro. É nesta perspectiva que eu sugiro aqui a construção da noção de experiência social, noção esta que designa as condutas individuais e coletivas dominadas pela heterogeneidade de seus princípios constitutivos, e pela atividade dos indivíduos que devem construir o sentido de suas práticas no próprio seio desta heterogeneidade (DUBET, 1994, p. 15).

6 Dubet (1994) compreende como sociologia clássica hegemônica não apenas a corrente positivista encabeçada por Durkheim, mas ainda o estrutural-funcionalismo, sociológico e antropológico, constituído por autores como Parsons, Kroeber, Malinowski e Radcliffe-Brow. Também se trata aqui das correntes teóricas cujas percepções abarcaram uma visão integracionista da sociedade (ainda que numa visão não estática), o que se estende desde os desdobramentos da teoria marxista, caso da Escola de Frankfurt e dos estudos de Adorno e Horkheimer. 
Nessa lógica, os indivíduos não são mais atores passivos que apenas assimilam as estruturas sociais, se constituindo através de uma variada gama de princípios culturais e sociais que, se incidem sobre suas condutas, possibilitam diversificados repertórios para suas ações (WAUTIER, 2003). É mediante tais pressupostos que Dubet define a subjetividade dos atores como objeto da sociologia da experiência, nos termos de uma sociologia da ação:

O objeto de uma sociologia da experiência social é a subjetividade dos atores. Esta sociologia compreensiva exige a dupla recusa da estratégia da suspeita e da ingenuidade da imagem de um ator totalmente cego ou totalmente clarividente. A posição escolhida assenta menos num postulado ontológico relativo à condição humana do que numa necessidade de método, porque a subjetividade dos atores, a consciência que eles têm do mundo e deles próprios, é a matéria essencial de que dispõe a sociologia da ação (DUBET, 1994, p. 100).

Se a heterogeneidade desponta como primeira característica constitutiva da experiência social, em segundo lugar Dubet afirma haver uma "distância subjetiva" entre ator e sistema, possibilitando estabelecer uma "reflexibilidade" que permite aos indivíduos encararem suas próprias vidas como experiência e não apenas em termos de execução de papéis sociais pré-definidos. Por último, a experiência social ainda se caracteriza por ser uma construção da experiência coletiva que procura superar a alienação. Na visão de Dubet (1994), a alienação é o que impede os atores de obterem a capacidade de gerenciamento de suas próprias experiências. Não havendo mais um conflito central na estrutura societária, nem projetos unificadores que engajem os indivíduos, o ator fica mais exposto em relação à alienação, o que desfavorece a construção de sua experiência. A alienação ocorre quando há um descontrole por parte do ator em relação à diversidade de lógicas de ação que o influenciam (DUBET, 1994). Por conseguinte, a experiência social é uma luta contra a alienação e uma busca pela afirmação de si na medida em que permite ao indivíduo tornar-se sujeito. Ela é ao mesmo tempo subjetiva, por ser uma representação que 
o ator faz do mundo vivido, e cognitiva, por se tratar de uma construção que este mesmo ator faz da realidade. Assim, a sociologia da experiência deve ser encarada como uma sociologia da agência humana, cujos objetivos consistem em captar as relações complexas e articuladas que se estabelecem entre ator e ação.

Visando compreender a multiplicidade de experiências sociais possíveis na sociedade contemporânea, Dubet (1994) elabora a noção de lógicas de ação, segundo tipologias ideais de inspiração weberiana. As lógicas de ação aqui teorizadas se dão através de três grandes sistemas que formam, na visão de Dubet (1994), o conjunto social, a saber: a comunidade; o mercado e o sistema cultural. Ocorre que cada um desses sistemas se encontra vinculado a uma lógica de ação típica. Dessa forma, a lógica da integração refere-se aos vínculos que os indivíduos estabelecem com a comunidade, ou seja, com aquele conjunto de relações definidas por proximidade e vínculos morais, como família, vizinhança e grupos de pertença mais estabilizados. Já a lógica estratégica refere-se aos interesses que o indivíduo tem em relação ao mercado, com respeito aos recursos materiais, status e posição social. Por sua vez, a lógica da subjetivação refere-se ao sistema cultural que permite ao ator desenvolver uma consciência de si e tornar-se, efetivamente, sujeito de si. A subjetivação, nessa perspectiva, é vista como a lógica do sujeito e a cultura é o que permite ao ator estabelecer "a crítica social como fundamento da ação", o que se dá a partir de suas experiências comuns cotidianas (WAUTIER, 2003, p. 184).

Apesar de o sistema cultural permitir a emergência da subjetivação, é sobretudo no interior do conflito social que se trava uma luta contra a alienação, nos espaços e momentos em que o indivíduo procura ser "autor" e não mero "espectador" de sua vida (WAUTIER, 2003). Dessa forma, a experiência social se dá a partir da articulação entre as diferentes lógicas de ação, que permitem ou não que o indivíduo construa sua identidade social. O objeto da sociologia da experiência de Dubet (1994) passa a ser o trabalho efetuado pelos atores no processo de construção dessa identidade, o que se dá por meio das tensões sociais entre as diferentes lógicas de ação que afetam os indivíduos. 
O foco na experiência da subjetividade e na multiplicidade de lógicas de ação possíveis não significa extirpar do exame outras unidades de análise sociológica centradas em referenciais coletivos. Para Dubet (1994), as classes sociais, por exemplo, ainda interferem na experiência social dos indivíduos, mas de modo distinto do que ocorria na emergência da modernidade, gerando-se confusão e dispersão dos sujeitos e também uma falta de identificação com sua posição na estrutura material da sociedade. Isso não significa que não existam formas de dominação que se estabelecem a partir das relações de classe, mas que emergiram novas formas de relação com o trabalho que, embora possuam importância fundamental para a realização do indivíduo, não comportam mais a exclusividade como matriz de significações (WAUTIER, 2003). E a partir dessa matização surgem novas formas de exclusão que ultrapassam a própria noção de classe, engendrando-se sentimentos generalizados de desigualdade e exclusão que vão além da posição econômica e nos quais "cada indivíduo vê no outro o reflexo de sua infelicidade, aquilo que é ou pode vir a ser" (WAUTIER, 2003, p. 197).

Nessa perspectiva, Dubet (1994) chama atenção para o processo de "desinstitucionalização das instituições", pois os processos sociais perderam o caráter de homogeneidade e as próprias instituições perderam a força e representatividade que detinham, na medida em que se tornam incapazes de inculcar valores de modo homogêneo junto aos atores. Todavia, como propõe Wautier (2003), a desinstitucionalização também abre espaço para a própria lógica da subjetivação, numa perspectiva através da qual o indivíduo passa por diversas provações para se afirmar como sujeito, devendo proceder a escolhas e assim exercitando sua capacidade de deliberação.

A sociologia da educação de Dubet (1994) parte da constatação de que a escola também sofreu transformações e perdeu força como instituição de socialização. Se na sociologia clássica a escola detinha o papel de transformar os valores sociais vigentes em normatizações e definir papéis sociais específicos, na atualidade suas atribuições perderam o sentido institucional clássico, observando-se uma multiplicidade de instâncias e contextos concorrentes no processo de socialização, o que gerou 
percepção generalizada acerca de uma espécie de crise da escola contemporânea. Assim, as reações dos agentes educacionais com relação a tais demandas passam a ser distintas e até mesmo opostas. Nesse quadro, Dubet identifica, por um lado, os "reacionários", tidos como "realistas", que defendem um retorno ao que consideram a função original da escola, a saber: uma instituição socializadora e integradora dos valores sociais. Para estes, o papel da escola deve ser o de buscar o êxito escolar, ou seja, uma aprendizagem efetiva que prepare os estudantes para o mundo social concreto, com ênfase no mercado de trabalho. No outro extremo temos os "pedagogistas", vistos como "assistentes sociais" que procuram levar em conta um papel mais inclusivo e assistencial das instituições escolares, objetivando mais uma formação integral dos sujeitos em detrimento das ideias de êxito escolar (DUBET, 1994).

Diante desse tensionamento, Dubet (1994) refere que aquilo que alguns categorizam como "crise" na realidade é resultado do fim de um modelo "institucionalizador de valores", o que poderia dar lugar a um "modelo mais político" de educação. Tal modelo político permitiria que os atores pudessem se articular a fim de promover sua autonomia e protagonismo. Segundo o autor, a cultura escolar também não pode mais ser vista com um estoque de saberes, necessitando adaptar-se à realidade hodierna uma vez que o próprio ator não é mais produto de uma cultura específica, estando “situado 'por cima' das culturas particulares" (DUBET, 1994, p. 157). Isso significa que o papel do espaço escolar deveria ser o da valorização do pensamento crítico e da resistência às formas culturais hegemônicas.

Ao mesmo tempo em que a escola não pode mais ser vista em seu aspecto exclusivamente institucional, Dubet (1994) ainda propõe que ela não deva ser percebida como empresa, limitando-se a responder às demandas do mercado. Em sua visão sobre a educação, a escola passa a gerir um tensionamento dialético entre a unidade do conjunto educacional e a diversidade das lógicas de ação emergentes na contemporaneidade, podendo estar mais ligada à lógica da integração (conectada ao sistema da comunidade), à lógica estratégica (ligada ao sistema do mercado), ou à lógica da subjetivação (ligada ao sistema cultural). É justamente neste último caso, percebido por 
Dubet (1994) nos termos de um "modelo político", que o espaço escolar permitiria o desenvolvimento das lógicas de subjetivação nas quais os atores, através dos conflitos e tensões sociais, podem estabelecer um pensamento crítico que abrirá espaço para a subjetividade, emergindo possibilidades concretas de deliberação, protagonismo e autonomia?

\section{Entre estrutura e ação na sociologia da educação: diálogos entre Bourdieu e Dubet}

Conforme discutido acima, a abordagem de Pierre Bourdieu pretende encontrar um ponto de intersecção entre a estrutura social e os atores, o que em sua praxiologia se resolve em torno do conceito de habitus. Embora o habitus seja concebido nos termos desse ponto de mediação, Bourdieu (1983) refere que os indivíduos assimilam comportamentos, práticas e valores que estão presentes na estrutura societária. Ou seja, os indivíduos não possuem total liberdade de ação e deliberação, mas tampouco são empurrados em uma direção involuntariamente, considerando-se o habitus como algo incorporado em longos períodos - desde o seio familiar à pertença numa classe social —, tornando-se parte do indivíduo e de sua personalidade, assim moldando seu comportamento, suas concepções de mundo e sua ação no mundo (BOURDIEU, 1983). Por isso, nesta visão, o indivíduo não chega a ser um objeto passivo, completamente; sua ação na sociedade não é determinada, mas resultado de escolhas, ainda que as mesmas sejam afetadas por um habitus específico. Nesse sentido, para o autor, e no que concerne às tensões entre estrutura

7 De fato, não é incomum a proliferação de instituições escolares mais ligadas às lógicas integradoras, valorizando-se os aspectos da socialização dos indivíduos, assim como espaços escolares adequados à lógica estratégica, projetando o êxito escolar como sinônimo de integração ao mercado. Na visão de Dubet (1994), entretanto, é o modelo político que, através do tensionamento entre as duas lógicas anteriores permite a construção de uma experiência social que propicie ao indivíduo ser protagonista de sua própria experiência. 
e ação, é como se o habitus representasse uma simbiose entre sociedade e indivíduo, sistema e agência.

Ampliando essas ideias, segundo Bourdieu (1983) a sociedade não pode ser concebida como totalidade homogênea, sendo necessário compreendê-la como reunião de diferentes campos sociais independentes, os quais possuem lógicas internas distintas e geradoras de habitus característicos que são incorporados pelos indivíduos em seu interior. O campo social aparece como uma forma de explicar a heterogeneidade e as contradições sociais existentes no interior da sociedade e, desse modo, a perspectiva bourdiana distingue-se do positivismo de Durkheim, que percebe o todo social como uma estrutura harmônica, e se aproxima da análise dialética de Marx, que vê as contradições existentes na dinâmica social, agregando à possibilidade de compreensão dessas contradições a dimensão simbólica das relações de poder. Contudo, é justamente o foco nessas relações de poder que reinsere sua perspectiva analítica junto a uma visão estrutural da sociedade, na medida em que os campos sociais e suas estruturas hierárquicas visam à reprodução. Como modo de se perpetuar, um campo tende a gerar estratégias que visam manter suas estruturas fixas o suficiente para que ele se mantenha; portanto, um habitus de um campo social visa à reprodução de práticas consolidadas. Dessa maneira, os indivíduos são levados a incorporar um habitus típico (o que beneficia a conservação das relações estabelecidas) desde que os capitais em disputa em cada campo direcionem aquilo que deve ser almejado em seu interior, fomentando o conflito pelas posições hierárquicas nessa repartição específica da sociedade.

No caso específico da educação, essa lógica se mantém. Aqui a reprodução se dá a partir de habitus característicos e em conjunto com as disputas dos capitais em jogo no espaço escolar, sejam eles de ordem social, econômica, cultural ou simbólica. Os capitais relacionados são instrumentos que perpetuam as desigualdades especialmente a partir do modo como as diferentes condições socioculturais dos indivíduos (no caso, os estudantes) influenciam suas trajetórias e seu desempenho escolar, considerando-se que os conteúdos valorizados na escola compõem um 
arbitrário cultural seletivo que valoriza os conhecimentos de determinados grupos. Uma vez que as diferenças econômicas e culturais explicitam um abismo de diferenças entre a aquisição e acesso a diferentes capitais no campo educacional, somando-se às diferenças entre o habitus familiar dos estudantes de classes sociais distintas, cria-se um processo contínuo de exclusão que favorece o fracasso escolar de determinados atores, embora tal realidade seja mascarada com frequência e explicada em termos de uma ideologia do mérito individual (BOURDIEU, 2007).

Decerto, tal modelo analítico tem se demonstrado fecundo para a percepção das relações de poder plasmadas no âmbito da educação contemporânea, configurando ferramenta teórica imprescindível para a avaliação das desigualdades perpetuadas em sistemas educacionais cujos parâmetros estejam constituídos pelas ideias de neutralidade e meritocracia. Como demonstram autores como Nogueira e Nogueira (2002) e Rodrigues (2007), a sociologia da educação Bourdiana parece ter muito a oferecer, sobretudo em contextos nos quais o debate público encontra-se permeado por discussões sobre as políticas de redistribuição e acesso aos sistemas de ensino, caso das políticas de cotas, ou ainda as análises sobre a relação entre a qualidade de ensino e o desempenho escolar.

Como exemplo dessas agendas de pesquisa encontra-se o trabalho de Pinheiro (2011). Em pesquisa realizada com professores de Física da educação básica a respeito do conceito de educação de qualidade e sobre as causas da precariedade do ensino atual no país, os entrevistados demonstravam ignorar os aspectos socioculturais que fazem perpetuar o fracasso escolar. Nessa lógica, a dimensão das relações de poder constatadas por Bourdieu emergem no próprio discurso dos professores entrevistados, que atribuem as deficiências de aprendizagem a uma espécie de "sinal dos tempos”, a ideologia do mérito individual sobressaindo-se. É aqui que reside o caráter contributivo do enfoque de Bourdieu, que desconstrói a premissa de uma educação neutra e igualitária que descende de uma visão otimista sobre a universalização dos processos educacionais amparada na ideia de mérito. Ao contrário, com sua visão Bourdieu demonstra não apenas que os estudantes não são indivíduos que competem no campo da educação em 
condições de igualdade, como ainda revela a ficção atrelada à ideia de neutralidade do espaço escolar, nesse caso ressaltando-se a existência de arbitrários culturais que privilegiam a bagagem cultural dos estudantes.

Contudo, se este enfoque orientado a uma visão estrutural dos processos educacionais permite a visualização das mencionadas relações de poder, como demonstram alguns autores (NOGUEIRA; NOGUEIRA, 2002), a mesma perspectiva pode correr o risco de enfatizar demasiadamente o poder do habitus em estruturar determinadas estratégias de relação com o campo educacional, do mesmo modo que a noção de campo (com sua estrutura endógena específica) pode preterir interferências múltiplas entre o contexto educacional e outros espaços sociais específicos, caso das relações com o mercado ou as comunidades adjacentes ao próprio espaço escolar. Dito de outro modo, pouca atenção é concedida neste modelo analítico para a percepção das ações contestatórias ou mobilizações políticas próprias do âmbito estudantil, assim como as complexas redes de relações sociais estabelecidas entre o contexto escolar e outras instâncias da sociedade.

É justamente esta a contribuição que parece advir dos modelos teóricos configurados a partir do enfoque acionalista, caso do trabalho de François Dubet. Como referido anteriormente, Dubet (1994) parte de uma análise que desconstrói a lógica da estrutura, abrindo espaço para uma compreensão do social a partir da conciliação das ações individuais. Longe de negar a incidência das estruturas sobre o indivíduo, Dubet (1994) esforça-se para demonstrar que, ao menos nas sociedades contemporâneas do pós-guerra, conceber a sociedade como um sistema homogêneo e integrado não só não faz mais sentido como pode nos conduzir a uma compreensão incompleta da realidade social.

O que Dubet quer dizer é que os indivíduos de um campo social específico (para usar o conceito bourdiano) não são afetados apenas pela lógica interna desse campo, ou seja, não estão mais afeitos a incorporar o habitus daquele campo de maneira homogênea, pois sofrem influências de outras lógicas dos campos adjacentes. Aliás, é possível avaliar que a leitura de Dubet (1994) nos conduz a uma visão em que os campos sociais não se encontram mais tão separados, cruzando-se entre si, cada vez 
mais, e em que há a tendência de que as lógicas de espaços sociais específicos estejam sobrepujadas de tal forma que os indivíduos se situem na condição de serem comprimidos por uma multiplicidade de lógicas, as quais podem ameaçar a construção de suas identidades sociais. Nesse sentido, para Dubet, o indivíduo situa-se num ponto em que é puxado ou empurrado para diferentes lados, por vezes opostos. O resultado pode levar a dois caminhos: primeiro, a dificuldade de se afirmar como sujeito, o que levaria a um processo de alienação (ou submissão "sem reflexão" a uma ou mais lógicas de ação); segundo, a partir de um processo de reflexão e elaboração crítica das lógicas que incidem sobre o indivíduo, este seria capaz de, dialeticamente, constituir sua própria identidade, tornando-se sujeito de si e autor da própria vida (WAUTIER, 2003). É este último sentido que Dubet chama de experiência social.

Cabe retomar que a experiência social, segundo Dubet (1994), surge no interior desse conflito dialético entre as diferentes lógicas de ação às quais os indivíduos estão submetidos, sendo aquilo que permite ao indivíduo se tornar sujeito. O sujeito, para Dubet, é o indivíduo capaz de elaborar a crítica e desenvolver autonomia. Entretanto, esse processo não é tão simples, uma vez que as lógicas de ação identificadas pelo autor, por vezes, podem matizar o processo de subjetivação. A lógica da integração, ligada à vida comunitária, por exemplo, tende a reforçar a aquisição de valores e práticas sociais que promovem e conservam os ideais da comunidade. Assim, a ação dos indivíduos que se submetem à lógica da integração apresenta menos condições de elaborar uma experiência social que os conduza a uma afirmação da identidade enquanto sujeitos. Nesse sentido, a lógica da integração aproxima-se do conceito de habitus de Bourdieu. No interior de uma comunidade social, o habitus é mais homogêneo e mais facilmente incorporado pelas individualidades. Por sua vez, a lógica estratégica, ligada ao mercado, reforça a ideia da adequação às estruturas sociais que visam à manutenção das tendências mercadológicas, levando o indivíduo a incorporar valores e comportamentos que lhes permitam adequar-se ao mercado. Novamente, um habitus se estabelece mais facilmente, e a luta pela posse de capitais específicos torna-se ainda 
mais forte. Entretanto, é no tensionamento entre a lógica da integração e a lógica estratégica que Dubet acredita encontrar a lógica da subjetivação, que permite ao indivíduo equilibrar as tensões entre a comunidade e o mercado, aqui emergindo a capacidade de reflexão crítica sobre seus condicionamentos: a partir de então, o indivíduo age sobre si mesmo, procurando gerir sua identidade social e tornando-se sujeito.

É nesse quadro descrito por Dubet (1994) que a educação passa a ter um papel fundamental, a saber: o de possibilitar a experiência social dos sujeitos enquanto processo de construção de identidade. Longe de negar as desigualdades escolares apontadas por Bourdieu, Dubet vê na escola uma abertura para um modelo menos "reprodutor" do que aquele descrito na análise bourdiana. Partindo da constatação de que a escola não é mais uma "instituição" (no sentido clássico), mas tendo em vista a heterogeneidade do mundo social, Dubet propõe que tal espaço não possa mais ser concebido como instrumento inequívoco de socialização ou reprodução, podendo a escola ser percebida nos termos de um modelo político de educação, que abra espaço para a lógica da subjetivação.

De fato, Dubet não nega a existência de outros modelos educativos, mais afeitos à lógica da integração ou à lógica estratégica (que incentivam a incorporação de valores morais estabelecidos ou a competitividade e a adequação aos padrões de mercado). Todavia, é possível identificar espaços escolares cuja lógica predominante seja a da subjetivação, nos quais a comunidade e o mercado, integração e estratégia, coexistam dialeticamente, promovendo-se um pensamento crítico que amplie a experiência social dos estudantes. O modelo político, segundo Dubet (1994), prevê que os estudantes possam se autoafirmar, mas, além disso, possam se organizar para subverter as demais lógicas e agir sobre as estruturas sociais que por vezes lhes apareçam como opressoras e desiguais. De modo reiterado, não se trata de negar as relações de poder incidentes sobre o sistema educacional, o que pode inclusive ser avaliado de acordo com a reflexão teórica sobre as diferentes lógicas de ação, mas de avaliar as possibilidades de ação por parte dos estudantes, como no caso das mobilizações coletivas e participações políticas que emergem nos contextos estudantis. 
Esta agenda de pesquisa fica clara em estudos como os de Silva (2008), que observou as formas de participação política dos estudantes de escolas públicas buscando compreender o modo como os alunos se inseriam nas discussões sobre a gestão escolar. Amparado nos conceitos de lógicas de ação, o trabalho concluiu que, para que a participação dos estudantes seja efetiva, o modelo de gestão escolar precisa dar condições para a existência da autonomia estudantil: ou seja, um modelo de escola que favoreça uma lógica de ação equidistante entre as perspectivas da integração e da estratégia, viabilizando-se a constituição das subjetividades. Tal exemplo explicita as contribuições da sociologia da educação de Dubet, que não nega as desigualdades sociais presentes nos processos educacionais, mas apresenta a possibilidade de que os sujeitos possam criar condições de se posicionarem e transformarem a realidade em que vivem.

\section{Considerações finais}

O tensionamento entre estrutura e ação, que se desenvolve desde o surgimento da sociologia clássica, antes de ser visto como um problema pode, na realidade, ser concebido nos termos de uma riqueza epistemológica que é característica das ciências sociais, observando-se diferenças de abordagem que mais sinalizam demandas de complementaridade teórica do que rechaço de concepções. Não se trata aqui de advogar em nome de um sincretismo teórico indiscriminado, mas de refletir-se sobre a possibilidade de conciliação de múltiplas abordagens em vista de se analisar sociologicamente questões específicas. É o caso da educação. Sendo o processo educacional indissociável de uma totalidade, em termos de estruturas sociais, ao mesmo tempo em que configurado pelas ações empreendidas por indivíduos concretos, cabe analisarmos as possíveis aproximações teóricas sinalizadas, o que aqui é efetuado a partir da comparação entre a praxiologia de Bourdieu e a sociologia da experiência de Dubet. Apesar de abordagens aparentemente opostas, sugere-se aqui que a interlocução entre tais perspectivas pode se apresentar como exercício 
analítico enriquecedor não apenas para a definição de novos objetos de pesquisa, mas, sobretudo, para o embasamento teórico dos mesmos.

Cabe, pois, questionar até que ponto o habitus, categorizado por Bourdieu, é mais atuante nos processos educativos do que a experiência social, conceituada por Dubet. Será a subjetivação um processo factível no espaço escolar? Ou, por outra via, estaremos fadados à reprodução social dentro deste mesmo espaço? Será o habitus moldável através do tensionamento das diferentes lógicas sociais que afetam os atores? Será o modelo político de educação uma forma de superar as desigualdades sociais e permitir que os atores construam sua identidade por meio da subjetivação? Em princípio, parece que a força do habitus é difícil de ser refutada e a observação cotidiana dos espaços escolares reforça a ideia de que a escola tradicional está ainda muito fortemente amparada em uma estrutura rígida de reprodução, a qual promove e perpetua desigualdades, incidindo sobre o desempenho escolar dos estudantes. Por outro lado, a observação mais atenta da percepção dos próprios atores sociais e da construção de suas experiências, apesar de não ignorar a existência das estruturas, pode revelar lógicas de resistência empreendidas pelos próprios estudantes e geradas dentro daqueles mesmos espaços escolares — visando resistir à tendência da reprodução e negando uma socialização passiva. Nesse caso, a consideração da experiência social projeta-se sobre as possibilidades de emergência de visões de mundo críticas e afirmação de identidades específicas, bem como subjetividades cujos contornos possam gerar reflexividade, deliberação e protagonismo estudantil.

Talvez Bourdieu e Dubet estejam falando de coisas diferentes, na medida em que um se preocupa com uma análise de cunho estrutural, partindo do todo para compreender a parte, enquanto o segundo estabelece sua análise considerando olhar a parte para se chegar ao todo. Sendo assim, partindo de princípios distintos é passível que se chegue a conclusões diferentes. Mas não será esta uma forma reducionista de interpretá-los? Resta-nos não sentenciar a validade de uma abordagem para negar a outra, mas mostrar que ambas as teorias podem ser úteis para fins diferentes e, principalmente, servem para manter vivas as tensões entre 
estrutura e ação, não nos deixando oscilar para perspectivas inequívocas. Apesar de estabelecerem aspectos teóricos e metodológicos distintos, os quais conduzirão objetivos diferentes, as sociologias de Bourdieu e Dubet permitem pontos de conexão e até complementaridade quanto às reflexões educacionais. Em síntese, estrutura e ação continuam provocando uma polarização que, longe de ser resolvida, permite um balanço e um equilíbrio dialógico que pode ser extremamente útil para uma compreensão mais fecunda das relações sociais que envolvem os processos educacionais.

\section{Referências}

ARENHART, D. O que move a ação dos indivíduos? Um diálogo com Pierre Bourdieu e François Dubet. Revista Pedagógica, Chapecó, v. 16, n. 33, p. 335-348, 2014.

BOURDIEU, P. Pierre Bourdieu: Sociologia. Org. Renato Ortiz. São Paulo: Ática, 1983. (Coleção Grandes Cientistas Sociais).

BOURDIEU, P. Questões de Sociologia. Lisboa: Fim de Século, 1984.

BOURDIEU, P. O Poder Simbólico. Rio de Janeiro: Editora Bertrand, 1989.

BOURDIEU, P. A escola conservadora: as desigualdades frente à escola e à cultura. In: NOGUEIRA, M. A.; CATANI, A. (Orgs.). Escritos de Educação. Petrópolis: Vozes, 2007. p. 39-64.

CARVALHO, M. C. B. Teorias da Ação em Debate. São Paulo: Cortez Editora, 1993. CATANNI, A. As possibilidades analíticas da noção de campo social. Educação e Sociedade, Campinas, v. 32, n. 114, p. 189-202, 2011.

DUBET, F. Sociologia da experiência. Lisboa: Instituto Piaget, 1994.

DURKHEIM, É. Durkheim: Sociologia. Org. José Albertino Rodrigues. São Paulo: Ática, 2000. (Coleção Grandes Cientistas Sociais). 
GAIGER, L. I. G. Por uma Sociologia Dialógica. Estudos Leopoldenses, São Leopoldo, v. 35, n. 155, p. 21-37, 1999.

IANNI, O. A sociologia e o mundo moderno. Tempo Social, São Paulo, v. 1, n. 1, p. 7-27, 1989.

LEISTNER, R. Proximidades e apartamentos entre Bourdieu e Touraine: algumas imbricações teóricas. Composição, Campo Grande, n. 5, ano 3, p. 81-99, 2009.

LEISTNER, R. O debate da Escola de Frankfurt e suas contribuições para uma reflexão crítica da sociedade contemporânea. Ciências Sociais Unisinos, São Leopoldo, n. 51, v. 2, p. 110-122, 2015.

MARX, K; ENGELS, F. A Ideologia Alemã. São Paulo: Hucitec, 1987.

NOGUEIRA, C. M.; NOGUEIRA, M. A. A sociologia da educação de Pierre Bourdieu: limites e contribuições. Educação e Sociedade, Campinas, n. 78, ano 23, p. 15-36, 2002.

ORTIZ, R. A procura de uma Sociologia da Prática. In: BOURDIEU, P. Pierre Bourdieu: Sociologia. Org. Renato Ortiz. São Paulo: Ática, 1983. p. 7-36. (Coleção Grandes Cientistas Sociais).

PINHEIRO, N. C. Educação de qualidade na perspectiva de professores de Física da educação básica: um estudo das interações discursivas em grupos focais, baseado na sociologia da educação de Pierre Bourdieu. Dissertação (Mestrado em Ensino de Física) - Programa de Pós-Graduação em Ensino de Física, Universidade Federal do Rio Grande do Sul, Porto Alegre, 2011.

RODRIGUES, A. T. Sociologia da Educação. [S. 1.]: Editora Lamparina, 2007.

SELL, C. Sociologia Clássica: Marx, Durkheim e Weber. Petrópolis: Vozes, 2010.

SILVA, R. M. D. Experiências sociais e lógicas de ação política: etnografia da participação estudantil na escola pública. Dissertação (Mestrado em Ciências Sociais) - Programa de Pós-Graduação em Ciências Sociais, Universidade do Vale do Rio dos Sinos, São Leopoldo, 2008. 
SILVA, R. M. D. O conceito de experiência social em François Dubet: algumas possibilidades analíticas. Mediações, Londrina, v. 14, n. 1, p. 275-290, 2009.

TOURAINE, A.; KHOSROKHAVAR, F. A procura de si: diálogo sobre o sujeito. Lisboa: Instituto Piaget, 2001.

WAUTIER, A. M. Para uma Sociologia da Experiência. Uma leitura contemporânea: François Dubet. Sociologias, Porto Alegre, ano 5, n. 9, p. 174-214, 2003.

WEBER, M. Economia e Sociedade: fundamentos da sociologia compreensiva. Brasília: Editora da Universidade de Brasília, 1994.

Recebido: 01/08/2018

Received: 08/07/2018

Recibido: 01/08/2018

Aprovado: 04/09/2018 Approved: 09/04/2018 Aprobado: 04/09/2018 